Research Article

\title{
Numerical Simulation and Experimental Study on Sealing Performance and Frictional Property of Rotary Lip Seal
}

\author{
Huifang Dong and Jian Hu \\ School of Mechanical Engineering, Chaohu University, Chaohu, Anhui, China \\ Correspondence should be addressed to Jian Hu; 303948098@qq.com
}

Received 16 March 2021; Revised 23 July 2021; Accepted 3 August 2021; Published 10 August 2021

Academic Editor: Veronica Calado

Copyright (c) 2021 Huifang Dong and Jian Hu. This is an open access article distributed under the Creative Commons Attribution License, which permits unrestricted use, distribution, and reproduction in any medium, provided the original work is properly cited.

\begin{abstract}
The hydrodynamic theoretical lubrication model of the friction pair between the rotary shaft and the lip seal under the state of full film lubrication was established in this paper. The Reynolds equation was solved by using the finite difference method, and the influence of the viscosity-temperature characteristics of the lubricant was taken into account in the solution process. The distribution of the film thickness and the hydrodynamic pressure in the sealing area was obtained. At the same time, the bench test was carried out and the correctness of the model was verified by comparing the simulation results and test results of reverse pumping rate and friction torque under different rotational speed of the shaft. The microasperity of the lip surface is a necessary condition for achieving the sealing effect. Therefore, the influences of the contact load of the seal and the root mean square deviation of the lip surface on the sealing performance and frictional property were analyzed by using the theoretical model. The analysis results show that the sealing performance and frictional property can be changed by changing the contact load and surface roughness of the lip, but a single increase in the influence of a certain factor cannot achieve good results, and comprehensive consideration is required in product design.
\end{abstract}

\section{Introduction}

Rotary lip seal is an indispensable form of sealing for media seal of transmission shaft, and its sealing performance is related to whether the machine can operate normally. Compared with other sealing methods, the rotary lip seal has the advantages of simple and compact structure, reliable performance, and excellent follow-up [1]. It is widely used in petrochemical machinery, vehicles and ships, aerospace, mining machinery, and agricultural machinery. It is one of the most common seals used at present [2].

Rotary lip seal realizes the sealing of lubricant through its reverse pumping effect. The reverse pumping effect is a unique phenomenon of the lip seal, which prevents the oil from leaking to the air side by sucking the oil back to the oil side. The reverse pumping mechanism believes that the hydrodynamic lubrication film will be formed between the lip of the lip seal and the surface of the shaft within the contact zone when the shaft rotates steadily. It is closely related to the microasperity of the lip surface. The shear stress of the oil film and the friction between the microasperity and the shaft when the shaft is rotating will cause shear deformation of the microasperity of the lip surface, coupling with the asymmetrical distribution of the contact pressure made by the asymmetric macrostructure of the lip seal, so that the microasperity of the lip surface will pump the lubricant from the air side back to the oil side like a screw pump, thereby realizing zero leakage [3-5]. The capacity of reverse pumping directly affects the sealing performance of the rotary lip seal.

As the working conditions of modern machinery develop in the direction of high temperature, high speed, and high pressure, rotary lip seals are facing more stringent performance requirements such as zero leakage, low friction, and long life. Therefore, continuous research on the lubrication and sealing performance of rotary lip seals is of great significance and has attracted widespread attention from scholars at home and abroad. With the development of 
computing technology, numerical simulation has gradually become an important research method. Scholars have established numerical models or carried out experiments to study the formation of the film between the two surfaces of lip seal and shaft [6-10] and study the influence of morphology of the asperities on the surface of the lip [11-16], the surface morphology of the shaft [17-19], the structural parameters of the lip seal [20], and the misalignment of the lip seal and shaft [21] on the sealing performance. Some scholars have also carried out experimental studies to explore the changing laws of the sealing performance under different operating conditions [22], the microstructure of shaft surface [23-25], and other factors. Studies have shown that there are two main aspects to evaluate the sealing performance of a lip seal: reverse pumping rate and friction torque. The reverse pumping rate is the key to the realization of zero leakage of the lip seal, and the friction torque reflects the degree of wear of the lip seal, which is two important factors for evaluating the performance of the lip seal.

There are many factors that affect the performance of the lip seal, but the final factor can be attributed to the distribution of the fluid pressure in the sealing area. Therefore, reasonable distribution of the flow field is very important to the sealing performance of the seal. Taking the friction pair of the rotary shaft and lip seal as the research object, a hydrodynamic lubrication model was established where the microasperities of the lip surface were simulated as cosine function and the influence of the viscosity-temperature characteristics of the lubricant was considered, and the distributions of film thickness and the hydrodynamic pressure in the sealing area were obtained by a numerical solution in this paper. At the same time, a bench test was carried out to verify the model. The correctness of the numerical model was verified by comparing the calculation results and test results of reverse pumping rate and friction torque at different speeds. Then, the influences of different contact forces of the lip seal and the surface roughness of the lip on the reverse pumping rate and friction torque were calculated and analyzed through the numerical model, which have important theoretical guidance for the prediction of the performance and service life and structural design of the lip seal.

\section{Hydrodynamic Lubrication Model}

A hydrodynamic lubrication model of the rotary lip seal is proposed based on the following basic assumptions:

(1) The two surfaces are fully film lubricated due to the effect of hydrodynamic pressure during the stable operation and do not consider contact.

(2) The shaft is regarded as completely rigid and has no axial movement; the lip seal is completely centered and completely elastic and has a uniform temperature.

(3) The lubricant is a Newtonian fluid and the flow is laminar. It can be considered that the density and viscosity of the lubricant remain unchanged in the thickness direction of the oil film because the film thickness is very thin.

(4) Do not consider changes of hydrodynamic pressure $p$ along the direction of the film thickness. The film thickness is much smaller than the radius of curvature of the lip seal and the shaft, so the effect of the curvature of the friction pair is not considered.

The schematic diagram of the contact area model of the lip seal at any position in the circumferential direction is presented in Figure 1, where $x$ represents the circumferential coordinate and $y$ represents the axial coordinate. The microasperity topography of the lip surface is simulated by a two-dimensional cosine form of periodic distribution. The calculation area is taken as the contact width $L$ in the axial direction and the period length $B$ in the circumferential direction and divided into $51 \times 51$ grids, and the external loads on each grid are assumed to be equal.

2.1. Reynolds Equation. A stable film is formed in the sealing area between the shaft surface and the lip surface when the lip seal is in a stable operation. The hydrodynamic lubrication control equation of the film in the contact area is the Reynolds equation and can be written as [6]

$$
\frac{\partial}{\partial x}\left(\Phi_{x} \frac{h^{3}}{12 \mu} \frac{\partial p}{\partial x}\right)+\frac{\partial}{\partial y}\left(\Phi_{y} \frac{h^{3}}{12 \mu} \frac{\partial p}{\partial y}\right)=\frac{U}{2} \frac{\partial h}{\partial x}+\frac{U \sigma}{2} \frac{\partial \Phi_{s}}{\partial x}+\frac{\partial h}{\partial t}
$$

in which $\Phi_{x}$ and $\Phi_{y}$ are pressure flow factors, and their physical meaning is the degree of obstruction of asperities to the fluid in flow driven by the pressure difference. For isotropic surfaces, $\Phi_{x}=\Phi_{y}$. $\Phi_{s}$ is shear flow factor; its physical meaning is the influence of additional flow generated when rough surfaces slide relative to each other. They can be obtained by the empirical formulas of Patir and Cheng [6], as shown in

$$
\begin{aligned}
& \Phi_{x}=1-0.9 \exp (-0.56 H), \\
& \Phi_{S}= \begin{cases}1.899 H^{0.98} \exp \left(-0.92 H+0.05 H^{2}\right), & H \leq 5, \\
1.126 \exp (-0.25 H), & H>5,\end{cases}
\end{aligned}
$$

where $H$ represents the dimensionless film thickness, defined as $H=h / \sigma, \sigma$ represents comprehensive roughness of the two surfaces, defined as $\sigma=\sqrt{\sigma_{1}^{2}+\sigma_{2}^{2}}, \sigma_{1}$ and $\sigma_{2}$ represent the root mean square deviation of the surface roughness of the lip and the shaft, respectively.

2.2. Film Thickness Equation. The surface topography of the shaft is negligible compared with that of the lip. The film thickness between the lip seal and the shaft is superimposed by the initial microasperity $f_{1}(x, y)$ of the lip surface, the axial curvature of the $\operatorname{lip} f_{2}(y)$, and the average film thickness $h_{\text {avg }}(t)$. The film thickness expression is given by 


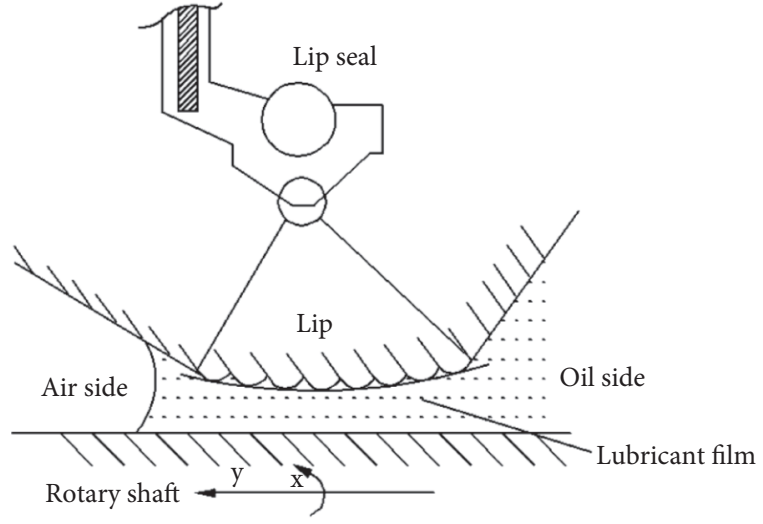

FIgURE 1: Schematic diagram of the contact area model of the lip seal.

$$
h(x, y, t)=h_{\mathrm{avg}}(t)+f_{1}(x, y)+f_{2}(y) .
$$

The periodic two-dimensional cosine form is considered to define the initial microasperity of lip surface, which is defined by the following expression:

$$
f_{1}(x, y)=h_{1} \cos \left(2 \pi N_{x}\left(x-d_{x}\right)\right)\left(1-\cos 2 \pi N_{y} y\right) .
$$

where $h_{1}$ is the wave amplitude of the lip seal surface, $N_{x}$ and $N_{y}$ are the number of periods of the lip surface in the $x$ and $y$ directions, and $d_{x}(y)$ is the circumferential shear deformation of lip surface, defined by

$$
d_{x}(y)= \begin{cases}D_{1} \cos \left[\frac{-\left(y-y_{\min }\right)}{y_{\min }} \cos ^{-1}(\Delta y)\right], & 0 \leq y \leq y_{\min }, \\ D_{1} \cos \left[\frac{\pi}{2\left(1-y_{\min }\right)}\left(y-y_{\min }\right)\right], & y_{\min } \leq y \leq L,\end{cases}
$$

where $\Delta y$ is the tangential deformation of the oil side relative to the maximum tangential deformation, $D_{1}$ is the ratio of the maximum tangential deformation to the undulation period in the $x$ direction, and $y_{\min }$ is the axial position where the initial average film thickness is the smallest.

The axial curvature of the lip is defined in the form of cosine, as in

$$
f_{2}(y)= \begin{cases}h_{2}\left[1-\cos \left(\frac{\pi}{2} \frac{y-y_{\min }}{y_{\min }}\right)\right], & 0 \leq y \leq y_{\min }, \\ h_{2}\left[1-\cos \left(\frac{\pi}{2} \frac{y-y_{\min }}{\left(1-y_{\min }\right)}\right)\right], & y_{\min } \leq y \leq L,\end{cases}
$$

where $h_{2}$ is the maximum film thickness in the axial direction.
2.3. Boundary Conditions. Reynolds boundary conditions are used as follows:

$$
\begin{aligned}
& p(x, 0, t)=p(x, L, t)=0.1 \mathrm{MPa}, \\
& p(0, y, t)=p(B, y, t), \frac{\partial p(x=0, y, t)}{\partial x}
\end{aligned}
$$

2.4. Load Capacity of Film. The load capacity of film and external load keep balance under the condition of hydrodynamic lubrication. The load capacity is equal to the integral of the pressure $p$ in the entire range of film, which can be obtained by

$$
W=\iint p(x, y, t) \mathrm{d} x \mathrm{~d} y .
$$

2.5. Reverse Pumping Rate. Once the distribution of the fluid pressure is determined, the reverse pumping rate can be calculated by equation (10). If $Q$ is a negative value, it indicates that the oil leaks from the oil side to the air side; if $Q$ is a positive value, it indicates that the oil is pumped from the air side to the oil side.

$$
Q=-\frac{1}{12 \mu} \int_{0}^{B}\left|h^{3} \frac{\partial p}{\partial y}\right|_{y=L} \mathrm{~d} x .
$$

2.6. Friction Torque. The friction torque is defined as the product of the fluid friction and the radius of the lip seal within the contact width. The friction torque determines the service life of the lip seal. It can be calculated by formula (11):

$$
T=\frac{D}{2} \oiint\left(\frac{\mu U}{h}+\frac{h}{2} \frac{\partial p}{\partial x}\right) \mathrm{d} x \mathrm{~d} y .
$$

2.7. Numerical Solution. The Reynolds equation is solved numerically using the finite difference method in this study. First, the Reynolds equation (1) is nondimensionalized and then discretized to obtain a linear equation system. A uniform grid is used, and the grid size is $51 \times 51$. The relaxation iteration method is used for loop iteration which has better convergence and faster convergence speed, and the iteration expression is obtained as equation (12). The relaxation factor is selected as $\omega^{\prime}=0.7$ based on calculation experience. The calculation process is shown in Figure 2.

$$
p_{i, j}^{k_{1}+1}=p_{i, j}^{k_{1}}+\omega^{\prime} \Delta p_{i, j}
$$

where $\Delta p_{i, j}=p_{i, j}^{k_{1}+1}-p_{i, j}^{k_{1}}$.

\section{Model Verification}

3.1. Test Equipment. The bench test was carried out on a selfmade lip seal testing machine, and its main structure is shown in Figure 3. The main technical parameters of the testing machine are (1) the speed range of the spindle: 


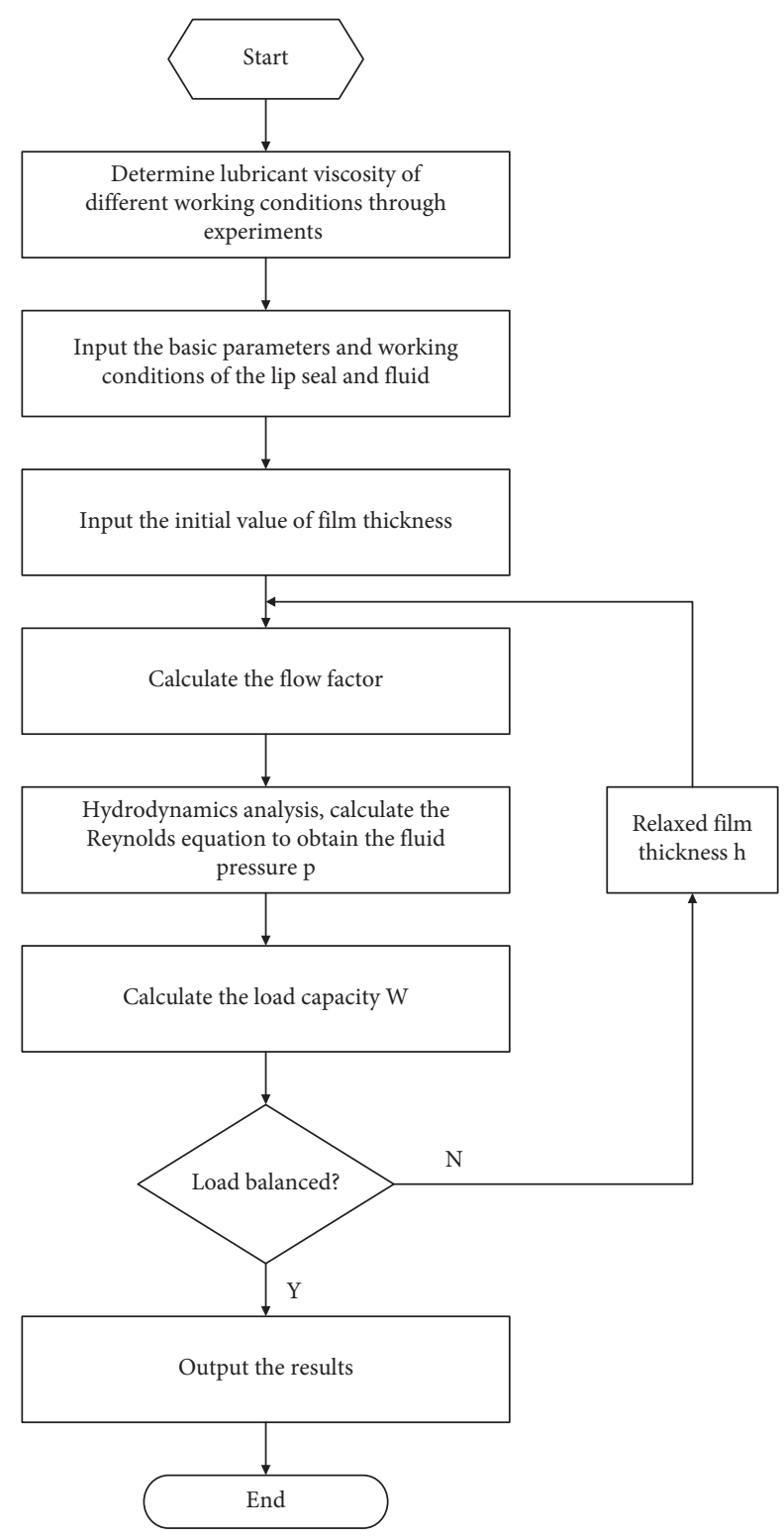

FIgURE 2: Flowchart of the numerical solution.

300 8000 r/min; (2) the maximum output torque of the motor: $20 \mathrm{Nm}$; (3) the radial runout of the spindle: less than $0.003 \mathrm{~mm}$. The main function of the test equipment is to test the performance of the rotary lip seal during operation, including the friction torque, pressure of oil chamber, temperature of oil chamber, leakage, and other parameters of different specifications of lip seals, which are used to study the frictional property and sealing performance of the lip seal.

The main composition and working principle of the testing machine: the testing machine is mainly composed of a main engine, an electric control cabinet, a lubricant source for the main shaft, a computer, and a lubricant source for the oil chamber. The motor can achieve stepless speed change from 300 to $8000 \mathrm{r} / \mathrm{min}$ through the frequency change of the frequency converter. The oil chamber is welded with stainless steel, and it is equipped with an oil inlet valve, a bleed valve, an oil return valve, and two temperature sensors, a pressure sensor and a torque sensor. Two temperature sensors are used to measure the temperature of the lip seal and the temperature of the oil chamber, respectively, the pressure sensor is used to measure the pressure in the oil chamber, and the torque sensor is used to measure the friction torque between the lip seal and the rotary shaft specimen. The lubricant source for the oil chamber is composed of an oil tank, an oil pump motor unit, a directacting relief valve, a high-temperature needle valve, and so on. The hydraulic oil pumped by the oil pump enters the oil chamber through the valve block and the oil inlet valve, and it indicates that the oil is full when the oil overflows through the bleed needle valve and then closes the bleed needle valve. The direct-acting relief valve can be adjusted from low to high to the required test pressure. The bleed needle valve should be opened and the oil pump motor should be stopped when the pressure test is not needed. The flow rate of the hydraulic oil is $2.5 \mathrm{~L} / \mathrm{min}$, and the pressure is $0-1 \mathrm{MPa}$. The electric control cabinet is mainly used to control the opening and closing of the frequency converter, the frequency conversion speed regulating motor, the lubricant pump of the main shaft, and the oil supply pump of the oil chamber, whose signal line is connected with the computer to realize the automatic control of the experimental process, data display and processing, and overlimit protection function in the experiment process. The test software matched with the hardware system of the testing machine can realize the functions of experimental parameter setting, parameter testing, display of dynamic data and graphics, and export of experimental results.

3.2. Sample Preparation. Studies have shown that if the surface of the shaft is too rough or too smooth, the lip seal will fail. The American Rubber Manufacturers Association, German standard DIN3760/3761, and international standard ISO6194/1 have stipulated the range of roughness of shaft surface. The ISO6194/1 requires that the seal contact surface of a ground shaft shall be finished to a surface roughness, measured in the axial direction of between $\mathrm{Ra} 0.2 \mu \mathrm{m}$ and $\mathrm{Ra} 0.5 \mu \mathrm{m}$ and between $\mathrm{Rz} 1.2 \mu \mathrm{m}$ and $\mathrm{Rz} 3.0 \mu \mathrm{m}$ [26]. Therefore, the outer surface of the rotary shaft sample was designed to be ground with a roughness $\mathrm{Ra}$ of about $0.4 \mu \mathrm{m}$ and $\mathrm{Rz}$ of less than $3.0 \mu \mathrm{m}$. The hardness of the shaft surface reaches HRC 55-60 after high-frequency quenching, which was measured on the HBRVU-187.5 optical hardness tester. The base material of the test rotary shaft is $45 \#$ steel, and its size is $\Phi 50 \mathrm{~mm} \times 35 \mathrm{~mm}$, as shown in Figure 4(a).

The surface roughness of the shaft was measured by the HT-SURF 10000 surface profiler. Figure 4(b) shows the twodimensional profile curve of the shaft surface. The two-dimensional roughness values of the shaft surface are $\mathrm{Ra}=0.345 \mu \mathrm{m}$ and $\mathrm{Rz}=2.798 \mu \mathrm{m}$ obtained by multiple measurements and taking the average value, which meet the standard requirements.

The material of the lip seal sample is NBR (nitrile rubber), the specification is TC50 $\mathrm{mm} \times 72 \mathrm{~mm} \times 8 \mathrm{~mm}$ 


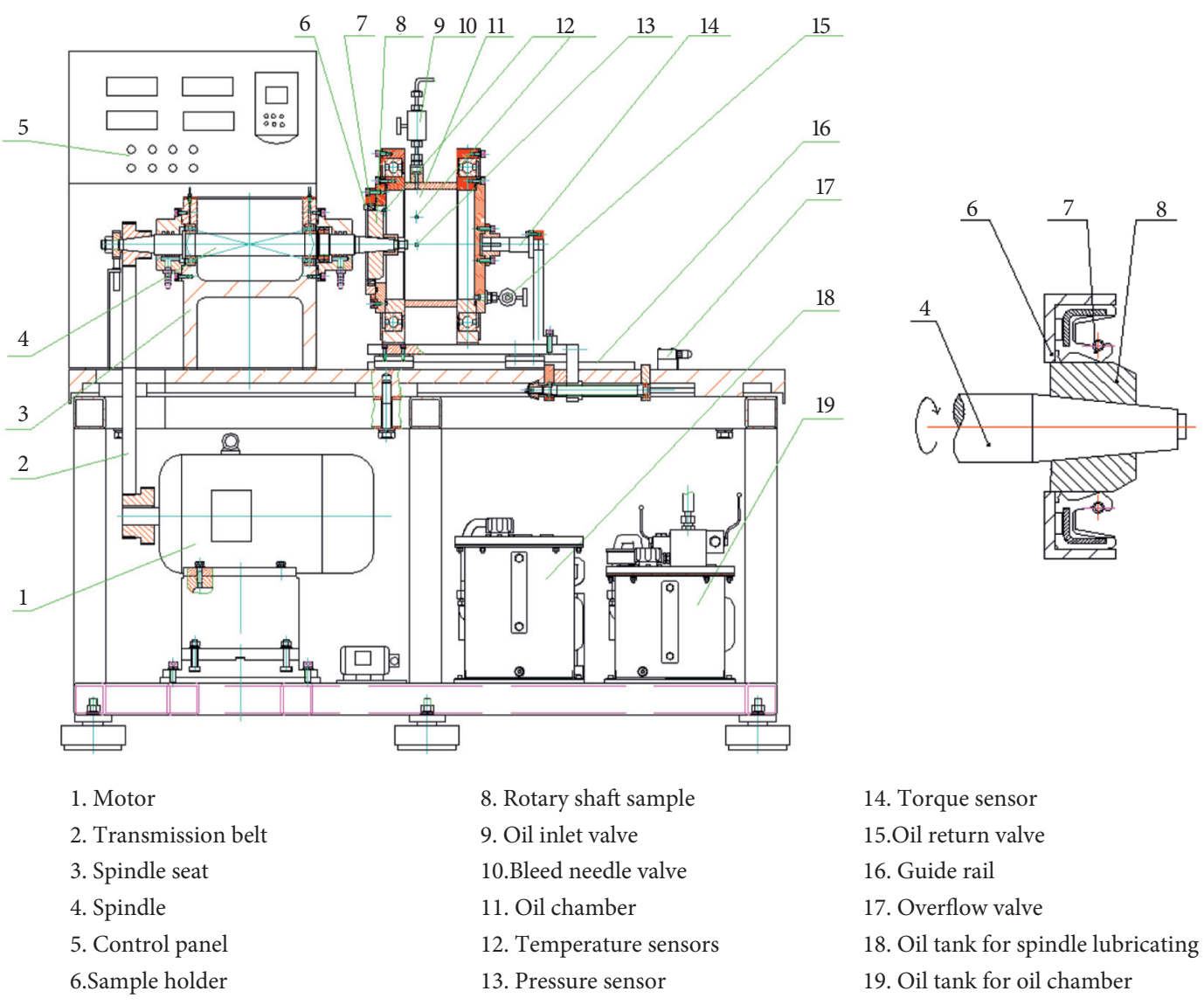

FIGURE 3: Schematic diagram of testing machine structure.

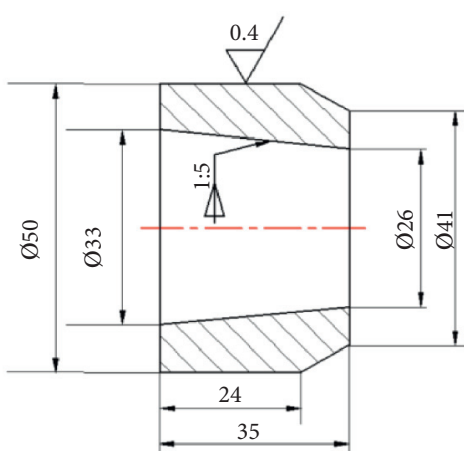

(a)

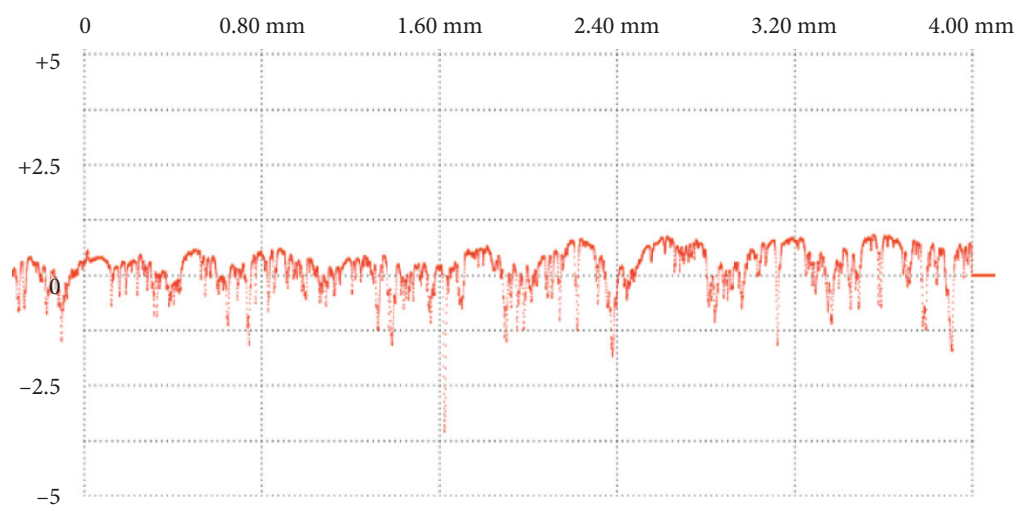

(b)

FIGURE 4: Information of rotary shaft sample. (a) Schematic diagram of dimensions. (b) Two-dimensional profile of the shaft surface.

(inner diameter $\times$ outer diameter $\times$ width), and the range of applicable temperature is $-40 \sim 120^{\circ} \mathrm{C}$. The lubricant is L-HL46 hydraulic oil, whose kinematic viscosity is $45.2 \mathrm{~mm}^{2} / \mathrm{s}$ at $40^{\circ} \mathrm{C}$ and $6.5 \mathrm{~mm}^{2} / \mathrm{s}$ at $100^{\circ} \mathrm{C}$. The density is about $0.87 \mathrm{~g} / \mathrm{cm}^{3}$.

3.3. Test Process. In order to fully consider the influence of the speed, the speed of the spindle was selected as $r=1000 \mathrm{r} / \mathrm{min}$,
$1500 \mathrm{r} / \mathrm{min}, 2000 \mathrm{r} / \mathrm{min}, 2500 \mathrm{r} / \mathrm{min}, 3000 \mathrm{r} / \mathrm{min}, 3500 \mathrm{r} / \mathrm{min}$, and $4000 \mathrm{r} / \mathrm{min}$. Since the testing machine has no heating function, the initial temperature of all tests is the ambient temperature of $25 \pm 2^{\circ} \mathrm{C}$. The surface of the rotary shaft sleeve sample was matched with the surface of the lip seal, and the test was carried out at different speeds for 120 minutes. The friction torque, temperature rise, and reverse pumping capacity of the friction pair corresponding to different speeds were measured, and the reverse pumping rate was calculated. 
The detailed experimental steps are as follows: (1) Mounting the sample: the lip seal was installed in reverse on the sample holder which can limit it in the axial and radial direction, and the sample holder is installed on the end face of the oil chamber by bolts after alignment. Then the rotary shaft sleeve specimen was installed on the main shaft and tightened with a nut for axial fixation. The oil chamber was moved to the left by turning the handle to the designated position where the lip seal was in contact with the surface of the rotary shaft sleeve specimen, and the locking screw was tightened to lock the moving table to prevent the position from changing during the experiment. (2) Power on: power on the electric control cabinet, turn on the computer, and enter the software interface to check whether the data displayed by each sensor were normal and whether there was an alarm signal. (3) Oil filling: open the oil inlet needle valve and the bleed needle valve, close the oil return needle valve, adjust the direct-acting relief valve to the lowest pressure, and press the "experimental oil pump on" button, and then the system starts to inject oil into the experiment chamber. It indicated that the oil in the cavity was full when it was found that there was oil flowing out of the oil pipe of the bleed needle valve, and the oil pump was turned off at this time. The level of the hydraulic oil in each test is consistent, which is subject to the filling of the oil chamber. (4) Setting the parameters and starting the experiment: set the information of the experiment, such as the alarm parameters, the duration of the experiment, the speed of the spindle, and the control mode, and then perform the experiment.

3.3.1. Measurement of the Temperature of the Seal Contact Area. It is difficult to directly measure the temperature of the contact area between the lip seal and shaft because there is relative movement between them, the contact width is only a few tenths of a millimeter, and the thickness of the film is as low as micrometers. Many scholars have adopted different measurement methods, such as perforating and burying a thermocouple in the lip near the contact area, using the oil temperature in the oil chamber to approximate the temperature of the contact area, using an infrared thermal imager to measure the temperature, and using the temperature of the shaft end to represent the temperature of the contact area. There are two temperature sensors on the testing machine in this study: one is installed on the oil chamber to measure the temperature of the oil chamber and the other is installed near the lip seal to measure the temperature of the oil seal. The measurement results of the temperature will be dynamically displayed on the interface of the supporting software during the experiment. The test results show that the temperature of the oil in the oil chamber is lower than the temperature of the lip seal, so it is more reasonable to regard the measured temperature of the lip seal as the temperature of the contact area, but there may be some errors in the temperature of the real contact area.

3.3.2. Measurement of Friction Torque. Friction torque is one of the key parameters for evaluating the sealing performance of rotary lip seal. The measurement of friction torque is mainly completed by the torque sensor of the testing machine and the test software. The torque sensor is connected to the computer, so the friction torque is displayed in real time during the whole operation. The initial temperature of the test is the ambient temperature of $25 \pm 2^{\circ} \mathrm{C}$. The friction torque and lubricant temperature change dynamically as the machine runs. The change rule of the friction torque with time contains the influence of the temperature change. It must be explained that the value of the friction torque discussed below is the value when its change is steady, and the lubricant bath temperature is the temperature corresponding to the time when the torque change is steady.

3.3.3. Measurement of Reverse Pumping Rate. Generally speaking, there are two main methods for measuring the reverse pumping rate which are the weighing method and the oil drop method. The lubricant is continuously supplied and almost the same conditions of oil supply are achieved in all tests in the former, while the injection of oil droplets is more error-prone and the result may be affected by the operator's operation in the oil drop method. Therefore, the weighing method was used to measure the reverse pumping rate in this study and the specific test process was as follows: the lip seal was installed in reverse, and the measured leakage was the reverse pumping capacity which can be known from the sealing mechanism described above. The oil sucked by the reverse pumping was collected by a beaker placed under the sample holder, and then the volume was measured with a small-capacity measuring cylinder. The bottom of the lip seal was exposed to the oil side when the lip seal was installed in reverse and the oil chamber was filled with oil, so the continuous supply of lubricant could be realized. The oil pumped could be collected in the beaker after a certain amount of time, and it flowed down the sample holder and dripped into the beaker only when enough oil is pumped. It started timing until the end of the experiment when the reverse pumping phase began and oil was observed to flow out of the sample holder, and the total time was recorded as $t$. Pour the oil collected in the beaker into a smallcapacity graduated cylinder to measure the total volumetric pumping capacity denoted as $m$. The volumetric reverse pumping rate is equal to the pumping capacity divided by the total pumping time.

\section{Results and Discussion}

It points out in the literature [27] that the film thickness $h$ in the contact area of the rotary lip seal during operation is about $0.1 \sim 1.0 \mu \mathrm{m}$ and may reach $10 \mu \mathrm{m}$ under large eccentricity; the contact width of the lip $L$ is generally $0.10 \sim 0.15 \mathrm{~mm}$ and increases to $0.2 \sim 0.3 \mathrm{~mm}$ after $500 \sim 1000$ hours of operation; the contact load of the new seal $F$ is in the range of $0.10 \sim 0.15 \mathrm{~N} / \mathrm{mm}$, and experience shows that the residual contact load of $0.05 \mathrm{~N} / \mathrm{mm}$ can maintain an effective seal [27]. But some scholars have measured a larger magnitude of film thickness; for example, Poll and Gabelli measured film thickness as high as $9.5 \mu \mathrm{m}$ when the speed is 
$1.4 \mathrm{~m} / \mathrm{s}$ [9], and Van Leeuwen and Wolfert measured the oil film thickness from $1 \mu \mathrm{m}$ at $0.035 \mathrm{~m} / \mathrm{s}$ to $4.5 \mu \mathrm{m}$ at $0.35 \mathrm{~m} / \mathrm{s}$ [10]. Therefore, the assignment of the initial value of the average film thickness is based on comprehensive consideration of the experiment results of Poll and Van Leeuwen.

The parameters of the sealing system studied in this paper are as follows: the diameter of the rotary shaft $D=50 \mathrm{~mm}$; the contact width of the sealing area $L=0.12 \mathrm{~mm}$; the length of the circumferential area $B=0.1 \mathrm{~mm}$; the initial average film thickness $h_{\text {avg }}=4 \mu \mathrm{m}$; the environmental pressure $p_{a}=0.1 \mathrm{MPa}$; the sealing pressure $p_{s}=0.1 \mathrm{MPa}$; the contact load $F=0.05 \sim 0.25 \mathrm{~N} / \mathrm{mm}$.

The reverse pumping rate and the friction torque are two important factors for evaluating the sealing effect and service life of the lip seal. Therefore, the above two parameters were selected as the research object to discuss the influence of viscosity of lubricant, rotational speed, contact load, and the surface roughness of lip surface.

4.1. Changes in Viscosity. In actual working conditions, the viscosity of the lubricant will drop sharply with the increase in temperature when the machine keeps running, especially at high rotational speeds. The change in viscosity will significantly affect the pressure distribution of the oil film, resulting in different reverse pumping rates and friction torque. In order to simulate the real working conditions more accurately, the temperature change of the lubricant at different rotational speeds was measured, while the machine is running during the test.

Figure 5 shows the change law of the temperature of lubricant when running for 120 minutes at $1000 \mathrm{r} / \mathrm{min}$. Figure 6 shows the change law of the temperature of lubricant at different speeds, where the temperature at each speed is the temperature that changes relatively smoothly during a period of operation. Figure 7 shows the variation of the viscosity of the No. 46 lubricant with the rotational speed obtained by using the viscosity-temperature characteristics of the lubricant.

\subsection{Distribution of the Film Thickness and the Hydrodynamic} Pressure. Bringing the above parameters into the numerical model of the hydrodynamic lubrication model shown in Figure 1, the distribution of the film thickness and hydrodynamic pressure is obtained when $h_{\text {avg }}=4 \mu \mathrm{m}, r=1000 \mathrm{r} /$ $\mathrm{min}$, and $F=0.1 \mathrm{~N} / \mathrm{mm}$. Figure 8 shows the distribution of film thickness in the contact zone, and Figure 9 shows the distribution of hydrodynamic pressure in the contact zone. It can be seen that the maximum fluid pressure is located at $0.3 \mathrm{~mm}$ in the direction of the contact width, close to the oil side, which is a necessary condition for achieving the reverse pumping effect according to the sealing mechanism of the lip seal.

4.3. The Influence of Rotational Speed. Figure 10 shows the calculation results and test results of the change law of reverse pumping rate of the lip seal in the rotational speed range of 1000 to $4000 \mathrm{r} / \mathrm{min}$. It can be seen that both indicate

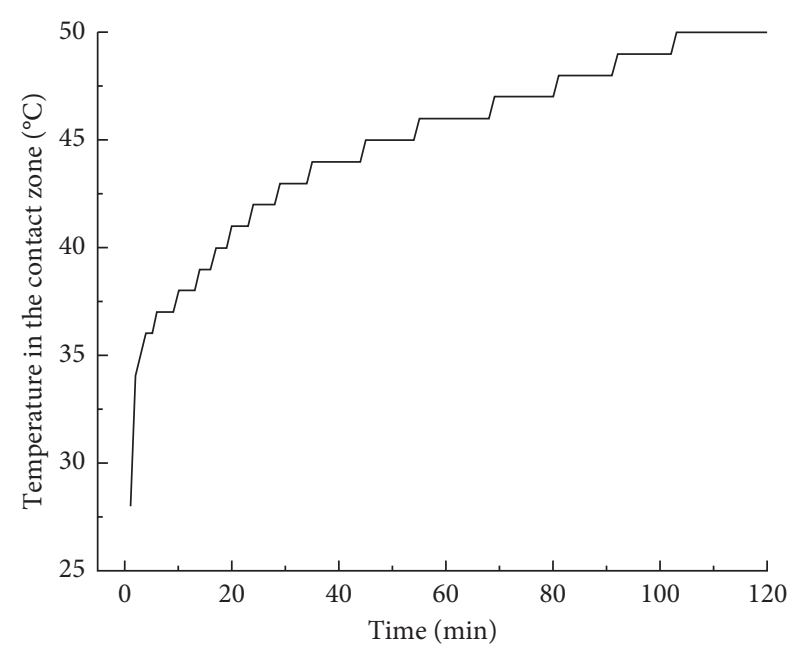

FIgURE 5: The change law of the temperature with time when the shaft speed is $1000 \mathrm{r} / \mathrm{min}$.

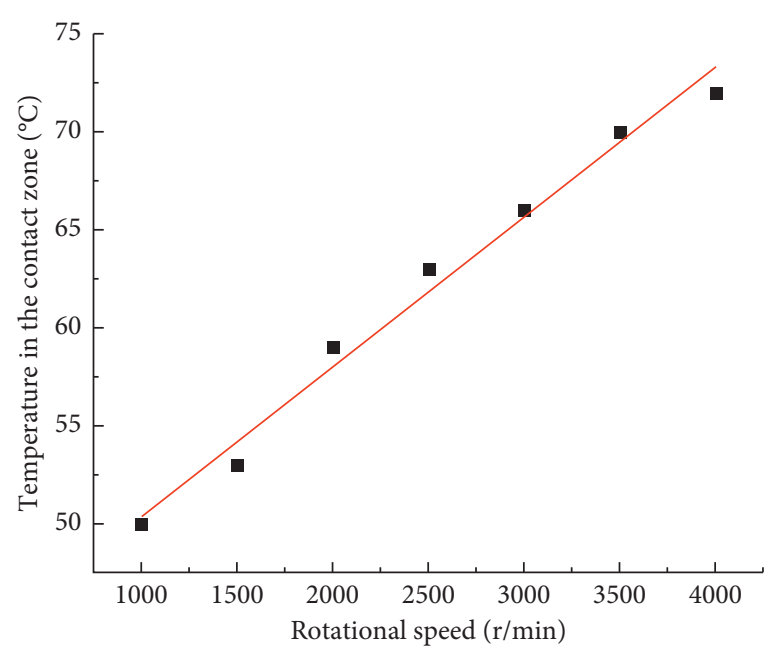

FIgURE 6: The change law of the temperature with rotational speed.

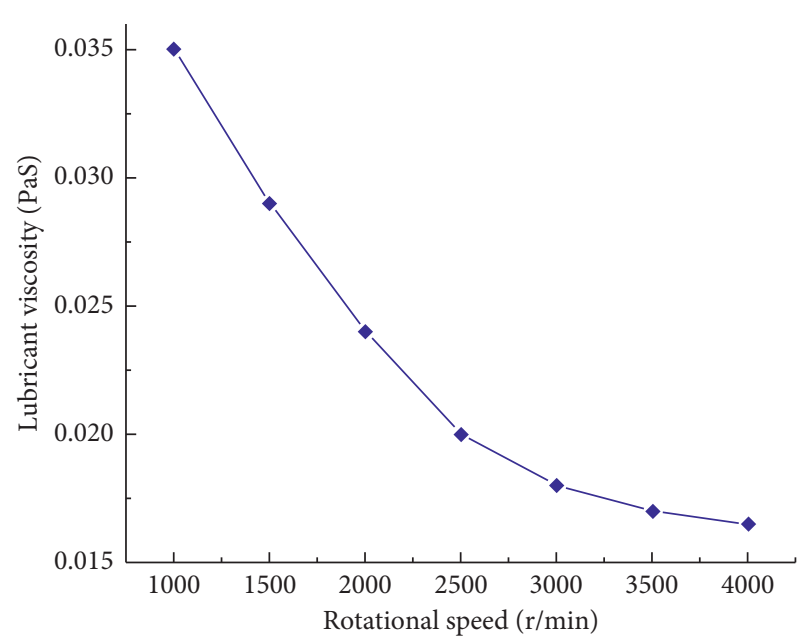

FIgURE 7: The change law of the lubricant viscosity with rotational speed. 


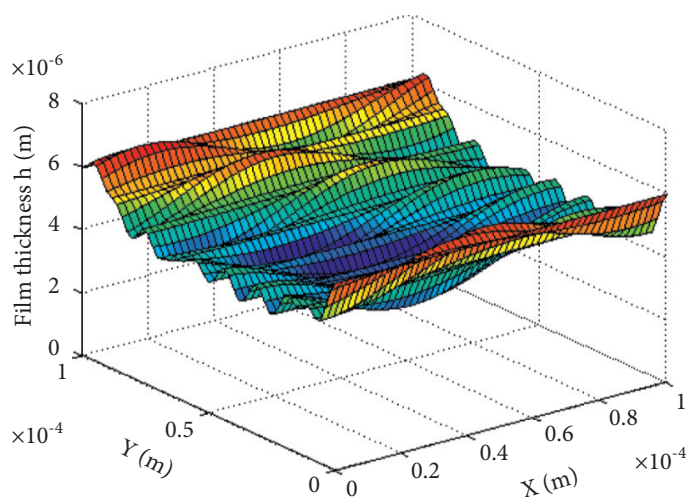

(a)

Figure 8: Distribution of film thickness in contact zone.

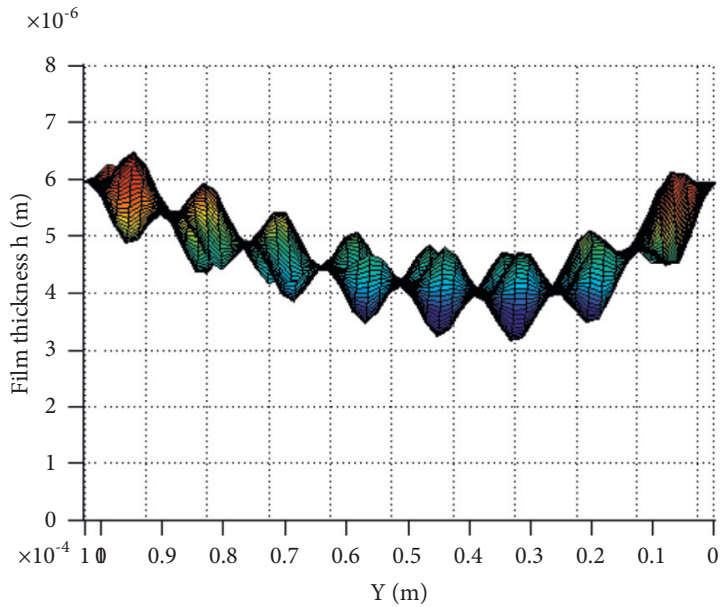

(b)

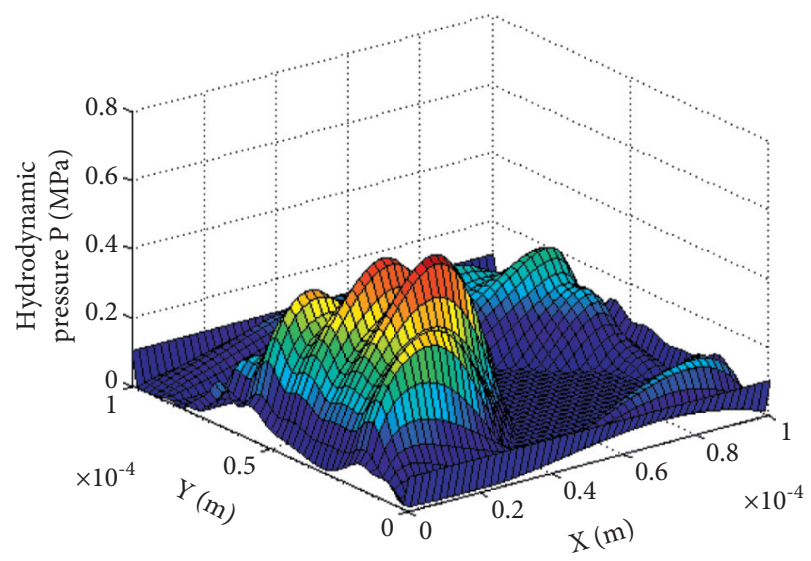

FIGURE 9: Distribution of hydrodynamic pressure in the contact zone.

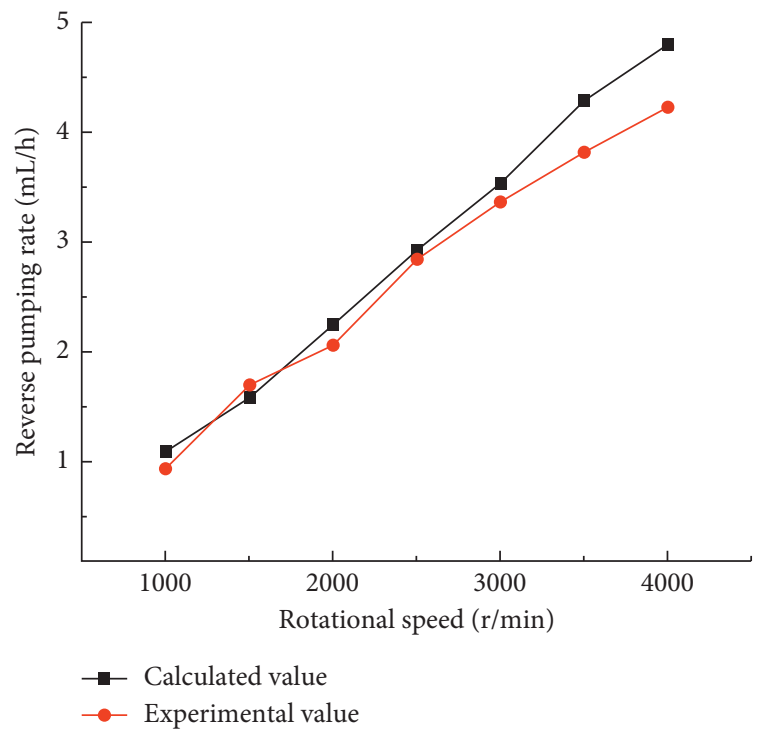

FIGURE 10: The change law of reverse pumping rate with rotational speed. that the reverse pumping rate increases with the increase of rotational speed, and the growth trend is basically linear. A large number of studies have shown that the reverse pumping rate is related to the speed of the shaft, but it is not reflected directly in formula (10). In fact, the influence of the speed is implicit in parameter $h$. The hydrodynamic pressure effect is enhanced, and the hydrodynamic support increases when the rotational speed of the shaft increases. Large support will create a large gap; therefore, the film thickness increases with the increase of the rotational speed, thereby increasing the reverse pumping rate.

The variation of friction torque with rotational speed is shown in Figure 11. Both theoretical calculations and test results show that the friction torque increases as the speed increases within the studied range, and the increase trend of friction torque gradually slows down when the speed exceeds $2500 \mathrm{r} / \mathrm{min}$. It can also be seen from equation (11) that the friction torque is proportional to the product of the viscosity of the lubricant and the speed of the shaft. The influence of the speed plays a major role when the speed is low; however, the viscosity of the lubricant decreases with the increase of the speed when the speed is increased, and the influence of the viscosity on it increases gradually.

The correctness of the hydrodynamic model of the lip seal is verified by the bench test. It can be seen that the changing trend of the theoretical values of reverse pumping rate and friction torque at different speeds is consistent with the experimental data generally from Figures 10 and 11, but there are differences in the consistency of specific values. The main reason for these differences is that, on the one hand, the amount of oil reverse pumped during the test is small, and there are certain errors in collection and measurement due to the limitation of the experimental instrument. On the other hand, the calculation results of the theoretical model are subject to the influence of the setting of some initial values of parameters and the idealized assumption of the operating state, and the model need be further optimized later. 


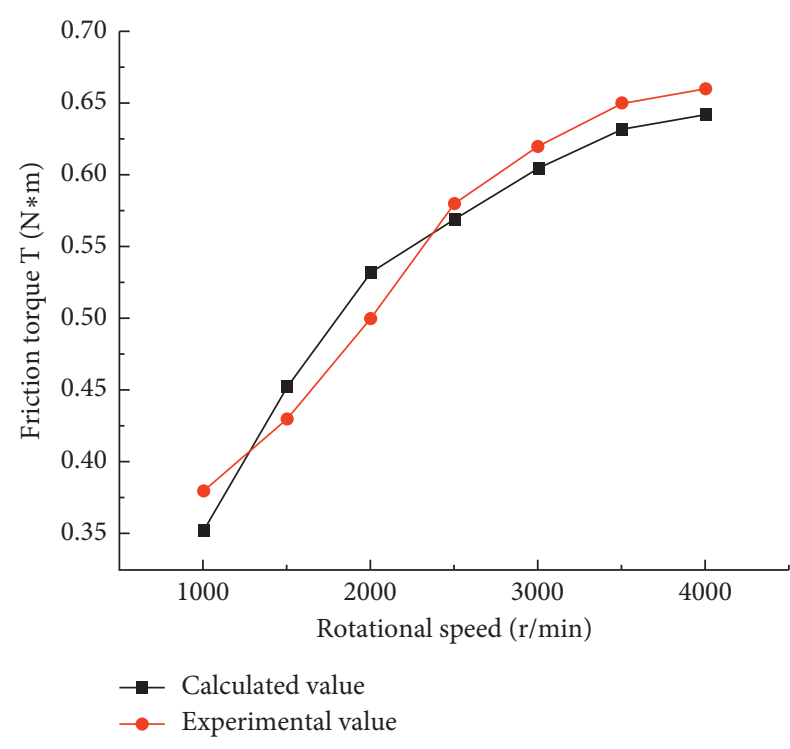

FIGURE 11: The change law of friction torque with rotational speed.

4.4. The Influence of the Contact Load of the Lip Seal. The microasperity of the lip surface is a necessary condition for the reverse pumping effect of the lip seal. Studies have shown that the microasperity of the lip surface generated during running-in and the contact force of the lip seal have a direct impact on the formation of the microasperity. Therefore, it is necessary to analyze the influence of different contact forces on the performance of lip seal. The change laws of the average film thickness, reverse pumping rate, and friction torque when the contact force of the lip seal changes from 0.05 to $0.25 \mathrm{~N} / \mathrm{mm}$ at $1000 \mathrm{r} / \mathrm{min}$ of speed are shown in Figures 12-14 separately. It can be seen from Figure 13 that the reverse pumping rate $Q$ decreases as the contact force $F$ increases. The reason is that high contact force leads to increased pressure in the gap of the seal, and fluid particles must overcome higher pressure to reach the air side from the oil side. At the same time, the film thickness in the contact zone decreases with the increase of contact force which can be seen from Figure 12, which leads to a decrease of flow from the air side to the oil side. It can be seen from Figure 14 that the friction torque $T$ increases as the contact force $F$ increases and the magnitude of the increase decreases gradually. This is because the average film thickness decreases with the increase of contact force, resulting in an increase in viscous shear friction of fluid.

4.5. The Influence of the Surface Roughness of the Lip. As can be seen from Figures 15 and 16, the numerical calculation results show that, within the range of research, the reverse pumping rate increases, while the friction torque decreases with the increase of the root mean square deviation of the lip surface, indicating that the sealing performance can be changed by changing the surface roughness of the lip. The trend of theoretical calculation is consistent with the results of Horve's test. Horve proved that the seal that has rough wear tracks with abundant microasperities provides better reverse pumping rates and excellent service reliability and

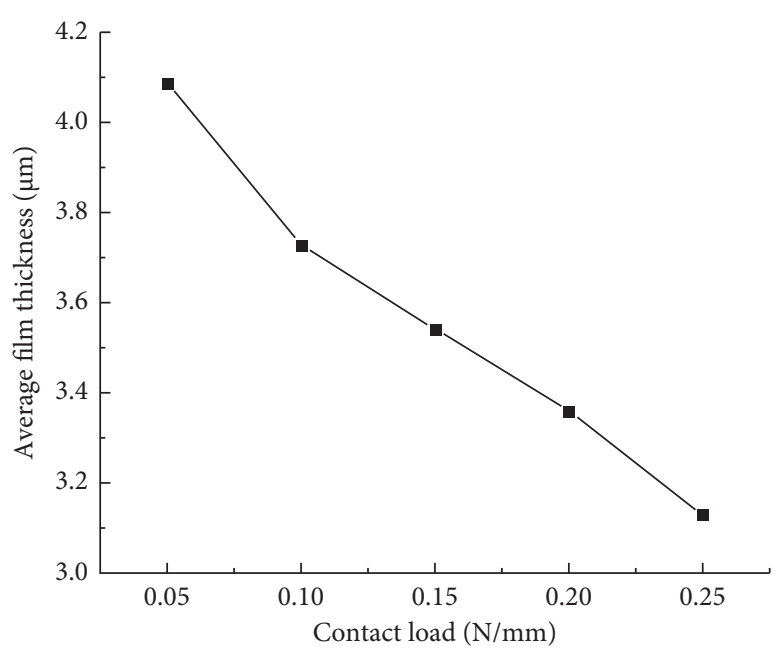

FIGURE 12: Average film thickness $h_{\text {avg }}$ varies with the contact force $F$ of the lip.

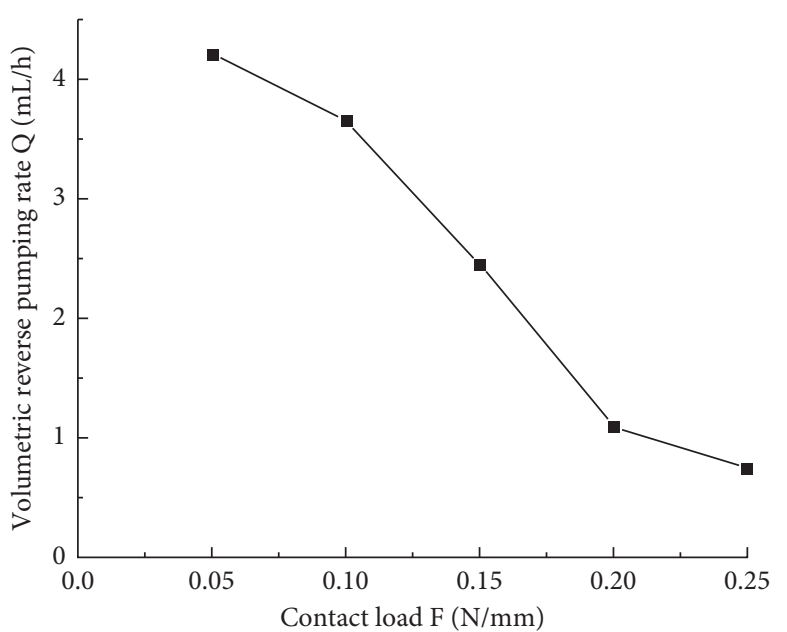

FIGURE 13: Reverse pumping rate $Q$ varies with contact force $F$ of the lip.

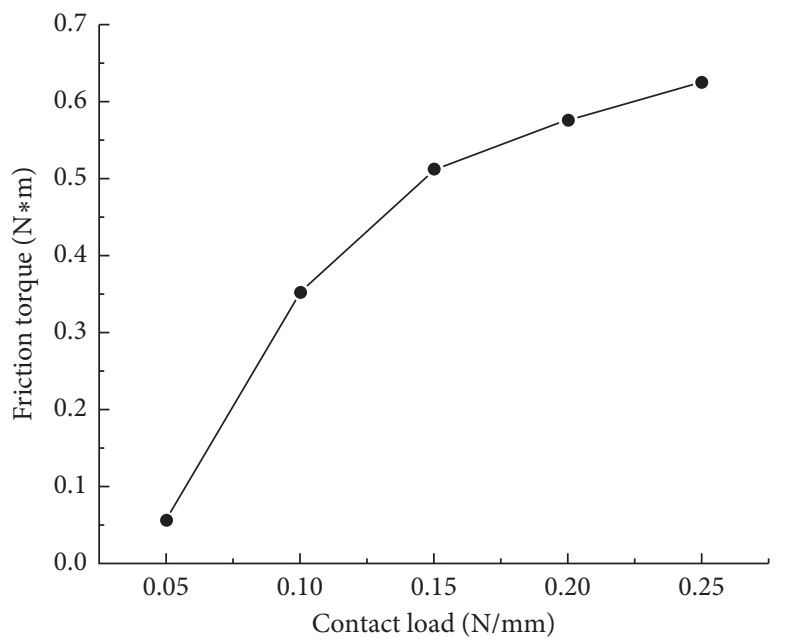

FIgURE 14: Friction torque $T$ varies with contact force $F$ of the lip. 


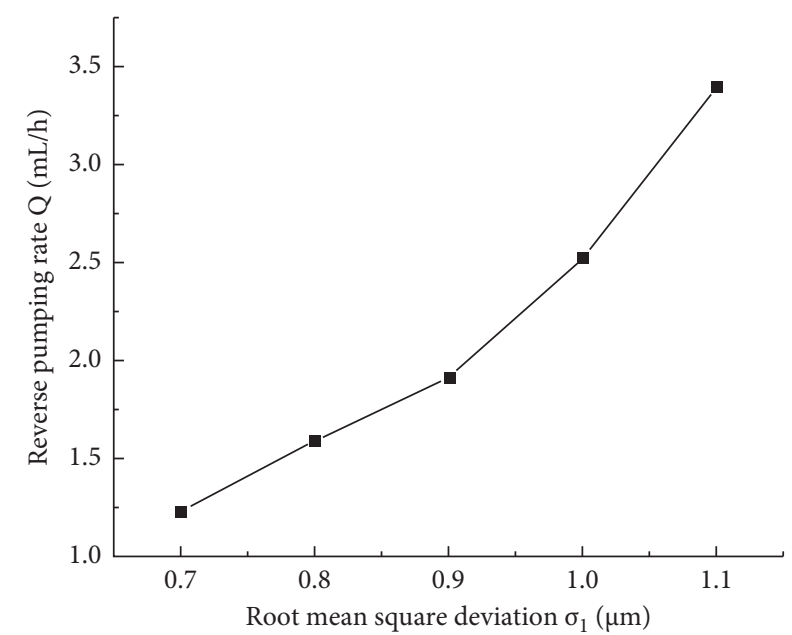

FIGURE 15: Reverse pumping rate $Q$ varies with the root mean square deviation $\sigma_{1}$.

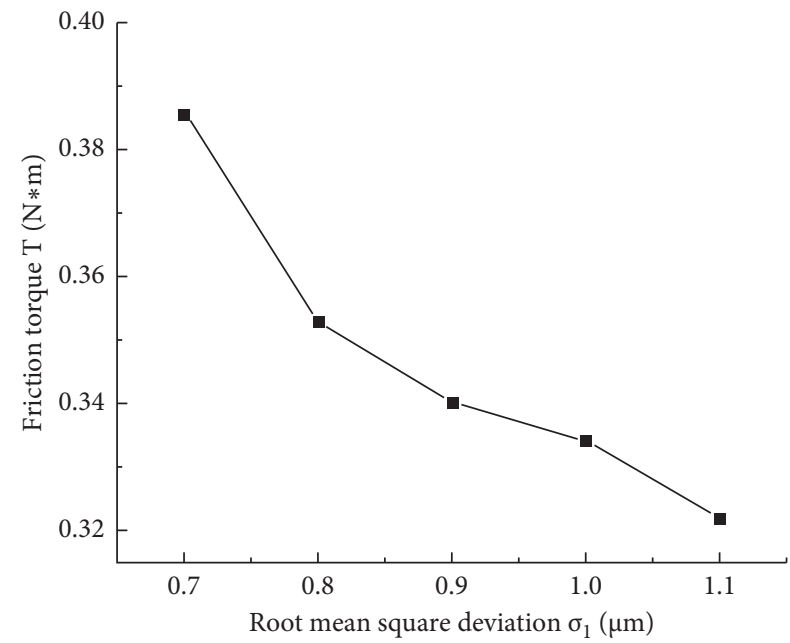

FIgURE 16: Friction torque $T$ varies with the root mean square deviation of the lip surface $\sigma$.

the smooth lip surface with no microasperities provides poor reverse pumping rates by experiments [11]. Obviously, the lip surface with abundant microasperities has greater surface roughness, while the smooth lip surface has smaller surface roughness. Reverse pumping ability and service reliability of the lip seal could be improved by artificially roughening the lip surface or changing the elastomeric material to provide the formulations of microasperities. But actual experience tells us that it will significantly increase the wear of the sealing ring and affect its service life if the surface roughness of the lip surface increases too much. Therefore, comprehensive consideration is required in product design.

\section{Conclusion}

(1) A numerical model for hydrodynamic lubrication of the interface between the rotary shaft and the lip seal was established in which the microasperities of the lip surface were simulated by a periodic two-dimensional cosine form and the influence of the change of lubricant viscosity was considered in the analysis. The distribution of film thickness and hydrodynamic pressure in the contact area was obtained by solving the model numerically.

(2) The reverse pumping rate and friction torque were selected which are the two most important parameters for evaluating the performance of the lip seal as the calculation output, and the correctness of the model was verified by carrying out a bench test.

(3) Rotational speed affects the reverse pumping rate indirectly by affecting the film thickness. In the range of research we did, the film thickness increases, and the reverse pumping effect is enhanced as the rotational speed increases. The friction torque increases with the increase of the speed. The friction torque is proportional to the product of the lubricant viscosity and the shaft speed. The influence of the speed plays a leading role at low speed, and the influence of viscosity increases when the speed increases.

(4) The contact load of the seal and the root mean square deviation of the lip surface were analyzed by using the theoretical model verified. The analysis results show that the sealing performance can be changed by changing the contact load and surface roughness of the lip, but a single increase in the influence of a certain factor cannot achieve good results, and comprehensive consideration is required in product design.

\section{Nomenclature}

$\begin{array}{ll}x: & \text { Radial rectangular coordinates } \\ y: & \text { Axial rectangular coordinates } \\ h: & \text { Film thickness } \\ p: & \text { Fluid pressure } \\ t: & \text { Time } \\ \sigma: & \text { Comprehensive roughness of the two surfaces } \\ \sigma_{1}: & \text { Root mean square deviation of the surface } \\ & \text { roughness of the lip } \\ \sigma_{2}: & \text { Root mean square deviation of the surface } \\ \mu: & \text { roughness of the shaft } \\ U: & \text { Dynamic viscosity of fluid } \\ \Phi_{x}: & \text { Pressure flow factors } \\ \Phi_{y}: \Phi_{s}: & \text { Shear flow factor } \\ H: & \text { The dimensionless film thickness, } H=h / \sigma \\ h_{\text {avg }}: & \text { The average film thickness } \\ f_{1}(x, y): & \text { The initial microasperity of the lip surface } \\ f_{2}(y): & \text { The axial curvature of the lip } \\ N_{x}: & \text { The number of periods of the lip surface in the } x \\ N_{y}: & \text { direction } \\ h_{1}: & \text { The number of periods of the lip surface in the } y \\ \mathrm{~d} x(y): & \text { The cirection } \\ & \text { The wave amplitude of the lip surface }\end{array}$


$\Delta y: \quad$ The tangential deformation of the oil side relative to the maximum tangential deformation

$D_{1}$ : The ratio of the maximum tangential deformation to the undulation period in the $x$ direction

$y_{\text {min }}: \quad$ The axial position where the initial average film thickness is the smallest

$h_{2}$ : The maximum film thickness in the axial direction

$W$ : The load capacity of the film

Q: $\quad$ Volumetric reverse pumping rate

T: $\quad$ Friction torque

$\omega^{\prime}$ : $\quad$ Relaxation factor

$k_{1}$ : $\quad$ Iterative times

D: $\quad$ Diameter of the rotary shaft

$r$ : $\quad$ Rotational speed of the shaft

Pa: Environmental pressure

Ps: $\quad$ Sealing pressure

F: $\quad$ Contact load.

\section{Data Availability}

The data used to support the findings of this study are included within the article.

\section{Conflicts of Interest}

The authors declare that there are no conflicts of interest regarding the publication of this paper.

\section{Acknowledgments}

This research was funded by the National Natural Science Foundation of China (Grant no. 51875152) and the Project of Natural Science Research of Colleges and Universities in Anhui Province, China (Grants nos. KJ2020A0674 and KJ2018A0456).

\section{References}

[1] H. Xu, The Seal, Metallurgical Industry Press, Beijing, China, 1999.

[2] P. Baart, P. M. Lugt, and B. Prakash, "Review of the lubrication, sealing, and pumping mechanisms in oil- and greaselubricated radial lip seals," Proceedings of the Institution of Mechanical Engineers-Part J: Journal of Engineering Tribology, vol. 223, no. 3, pp. 347-358, 2009.

[3] D. Chan, "Sealing mechanism and main structural parameters of crankshaft rubber lip oil seal," Chinese Internal Combustion Engine Engineering, vol. 5, pp. 10-13, 1984.

[4] M. Kammüller, On Sealing of Radial Shaft Seals, University of Stuttgart, Stuttgart, Germany, 1986.

[5] H. K. Müller, "Concepts of sealing mechanism of rubber lip type rotary shaft seals," in Proceedings of the 11th BHRA International Conference on Fluid sealing, pp. 698-709, Cannes, France, 1987.

[6] N. Patir and H. S. Cheng, "Application of average flow model to lubrication between rough sliding surfaces," Journal of Lubrication Technology, vol. 101, no. 2, pp. 220-229, 1979.

[7] A. Gabelli, "Micro-elastohydrodynamic lubricant film formation in rotary lip seal contacts," in Proceedings of the 15th Leeds-Lyon Symposiumon Tribology, pp. 57-68, Leeds, UK, September 1989.
[8] A. Gabelli and G. Poll, "Formation of lubricant film in rotary sealing contacts: part I-lubricant film modeling," Journal of Tribology, vol. 114, no. 2, pp. 280-287, 1992.

[9] G. Poll and A. Gabelli, "Formation of lubricant film in rotary sealing contacts: part II-a new measuring principle for lubricant film thickness," Journal of Tribology, vol. 114, no. 2, pp. 290-296, 1992.

[10] H. J. Van Leeuwen and M. A. Wolfert, "The sealing and lubrication principles of plain radial lip seals: an experimental study of local tangential deformations and film thickness," in Proceedings of the 23rd Leeds-Lyon Symposium on Tribology, pp. 219-232, Amsterdam, Netherland, September 1996.

[11] L. Horve, "The correlation of rotary shaft radial lip seal service reliability and pumping ability to wear track roughness and microasperity formation," Journal of Passenger Cars, SAE Trans., vol. 100, 1991.

[12] R. F. Salant, "Elastohydrodynamic model of the rotary lip seal," Journal of Tribology, vol. 118, no. 2, pp. 292-296, 1996.

[13] R. F. Salant, “Modelling rotary lip seal," Wear, vol. 207, no. 1, pp. 92-99, 1997.

[14] R. F. Salant, "Theory of lubrication of elastomeric rotary shaft seals," Proceedings of the Institution of Mechanical Engineers-Part J: Journal of Engineering Tribology, vol. 213, no. 3, pp. 189-201, 1999.

[15] M. Hajjam and D. Bonneau, "Elastohydrodynamic analysis of lip seals with microundulations," Proceedings of the Institution of Mechanical Engineers - Part J: Journal of Engineering Tribology, vol. 218, no. 1, pp. 13-22, 2004.

[16] A. Maoui, M. Hajjam, and D. Bonneau, "Effect of 3d lip deformations on elastohydrodynamic lip seals behaviour," Tribology International, vol. 41, no. 9-10, pp. 901-907, 2008.

[17] W. Li, L. S. Stephens, and J. F. Wenk, "Experimental benchmarking of the numerical model of a radial lip seal with a surface textured shaft," Tribology Transactions, vol. 56, no. 1, pp. 75-87, 2013.

[18] F. Guo, X. Jia, Z. Gao, and Y. Wang, "The effect of texture on the shaft surface on the sealing performance of radial lip seals," Science China Physics, Mechanics \& Astronomy, vol. 57, no. 7, pp. 1343-1351, 2014.

[19] K. Emilia, N. Petros, R. Ramin, M. Nick, and R. Homer, "Effect of shaft surface roughness on the performance of radial lip seals," Lubricants, vol. 6, no. 4, p. 99, 2018.

[20] X. H. Jia, F. Guo, L. Huang, Q. Fan, and Y. Wang, "Structure optimization of lip seals based on a mixed lubrication model," Lubrication Engineering, vol. 38, no. 8, pp. 1-5, 2013.

[21] F. X. Borras, M. B. de Rooij, and D. J. Schipper, "Misalignment-induced micro-elastohydrodynamic lubrication in rotary lip seals," Lubricants, vol. 8, no. 2, p. 19, 2020.

[22] Y. Zhou, X. J. Liu, W. Wang, and K. Liu, "Experimental study on the friction characteristics and pumping effect of lip seal," Lubrication Engineering, vol. 36, no. 8, pp. 74-78, 2011.

[23] K. H. Warren and L. S. Stephens, "Effect of shaft microcavity patterns for flow and friction control on radial lip seal performance-a feasibility study," Tribology Transactions, vol. 52, no. 6, pp. 731-743, 2009.

[24] V. Kanakasabai, K. H. Warren, and L. S. Stephens, "Surface analysis of the elastomer in lip seals run against shafts manufactured with micro-cavity patterns," Proceedings of the Institution of Mechanical Engineers-Part J: Journal of Engineering Tribology, vol. 224, no. 8, pp. 723-736, 2010. 
[25] H. F. Dong, K. Liu, W. Wang, and X. J. Liu, "Laser textured shaft surfaces on the pumping action and frictional properties of lip seals," Tribology, vol. 32, no. 2, pp. 126-132, 2012.

[26] Iso 6194-1:2007, Rotary Shaft Lip-Type Seals Incorporating Elastomeric Sealing Elements-Part 1:Nominal Dimensions And Tolerances, ISO, Geneva, Switzerland, 2007.

[27] H. K. Miller and S. Bernard, Fluid Sealing Technology: Principle and Application, Machinery Industry Press, Beijing, China, 2002. 